
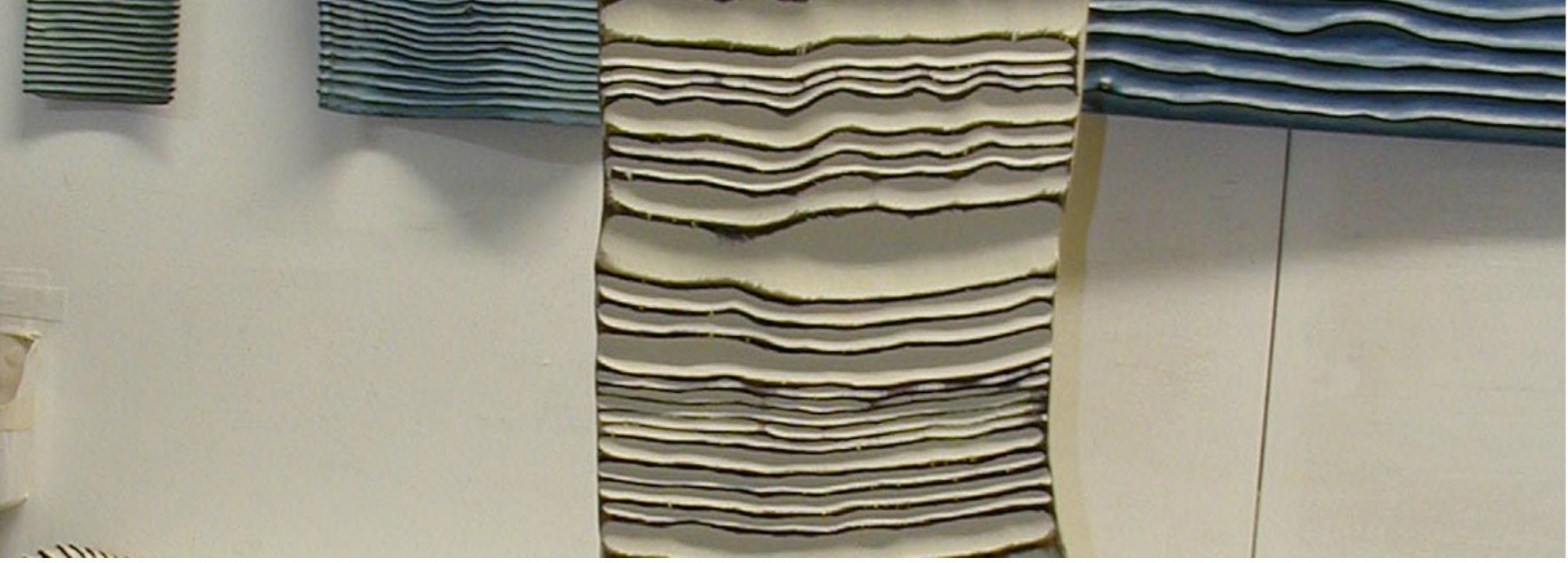

The 1971 War on Cancer Revisited

$\begin{aligned} \text { Authors: } & \text { Roland Mertelsmann } \\ \text { Submitted: } & \text { 2. November } 2016 \\ \text { Published: } & 5 . \text { November } 2016 \\ \text { Volume: } & 3 \\ \text { Issue: } & 6 \\ \text { Keywords: } & \text { cancer, evolution, bioethics, symposium } \\ \text { DOI: } & 10.17160 / \text { josha.3.6.245 }\end{aligned}$




\title{
THE 1971 WAR ON CANCER REVISITED
}

\section{Symposium Science, Ethics and Arts}

\author{
October 14, 2016
}

Prof. em. Dr. Drs. h.c. Roland Mertelsmann

Department of Medicine I, Hematology, Oncology, Stem Cell Transplantation

Freiburg University Medical Center

International Master Program of Biomedical Sciences (IMBS)

BIOTHERA-Foundation

JOSHA - Journal of Science, Humanities and Arts 


\section{THE WAR ON CANCER Continues 2016}

„For the loved ones we ve all lost, for the families that we can still save, let's make America the country that cures cancer once and for all“"

President Barack Obama, State of the Union Address, Jan 12, 2016

Aiming High - Changing the Trajectory for Cancer

Lowy \& Collins, NEJM April 2016 
Cancer:

The Emperor of All Maladies

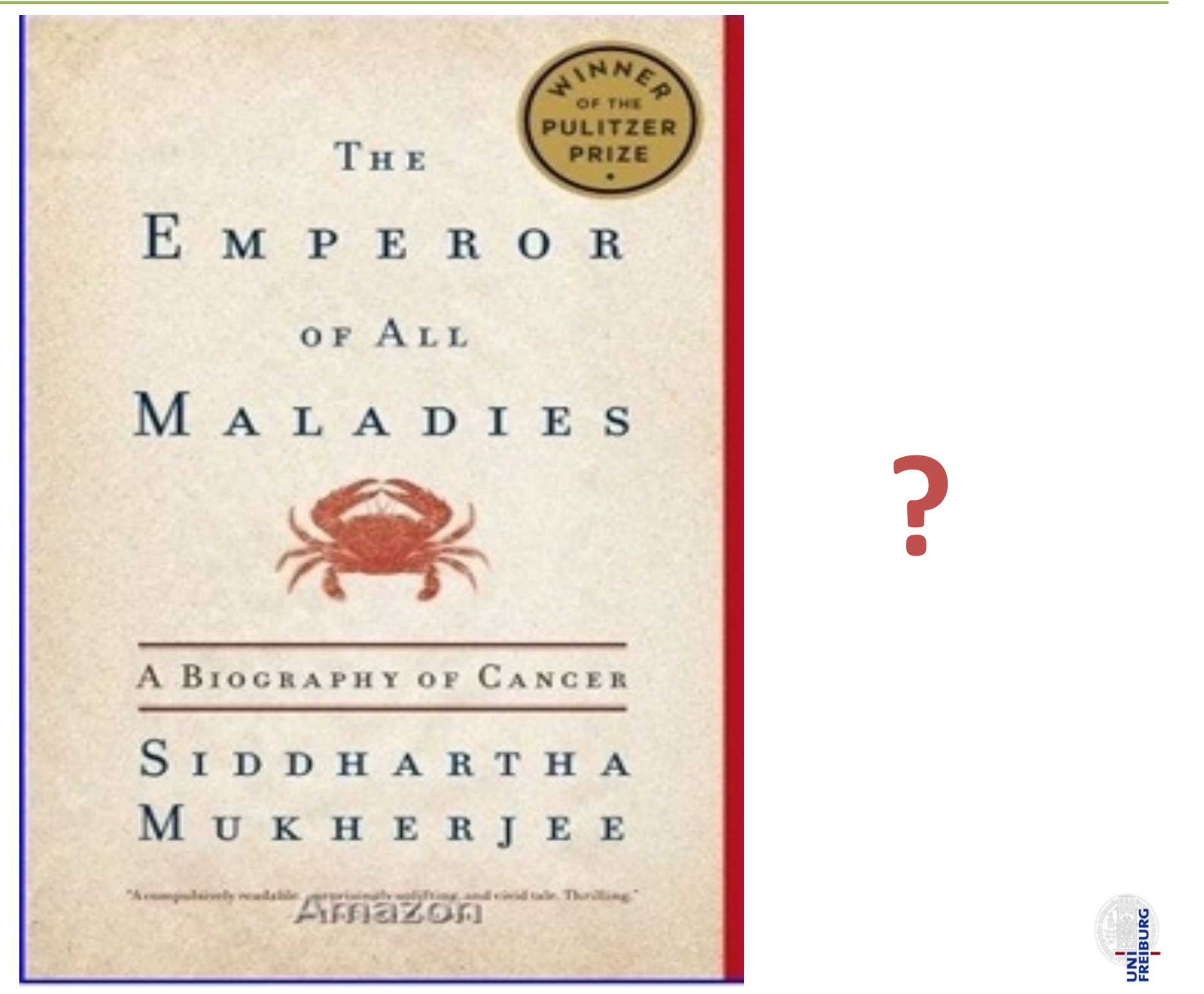




\section{Oncogenesis}

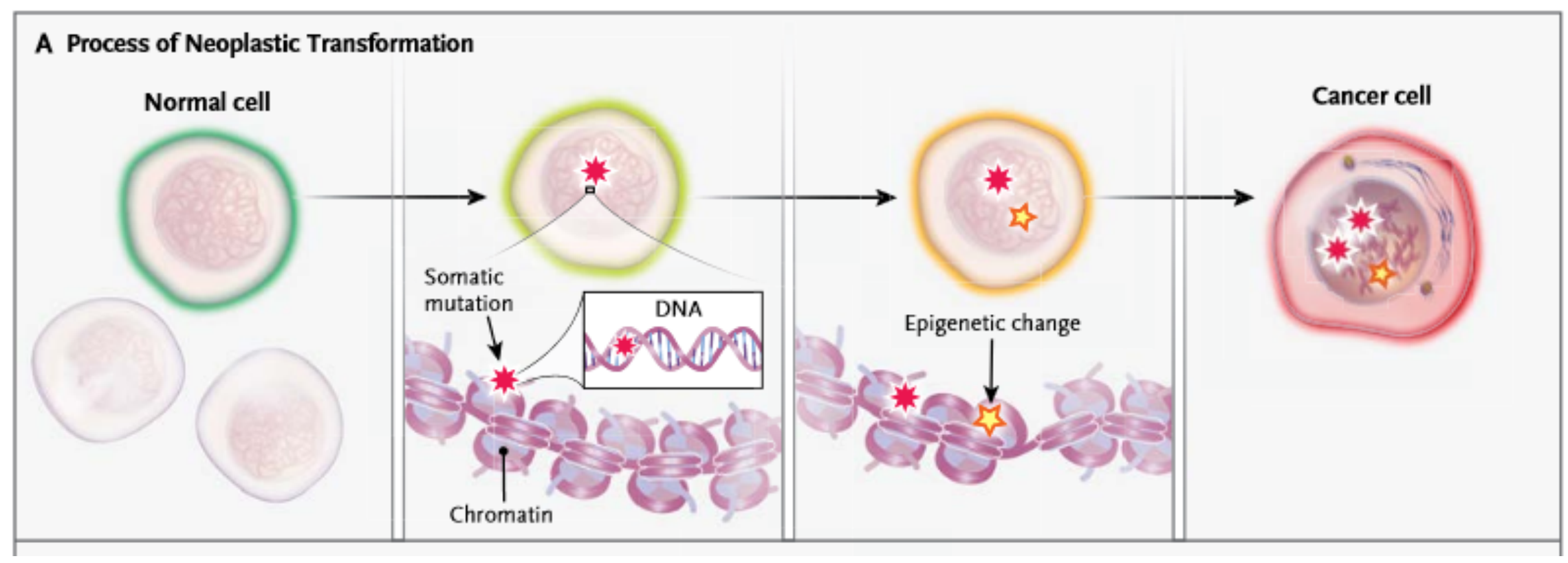

Increasing autonomy, genetic instability and

L. Luzzatto, P.P. Pandolfi, NEJM 373, 84, 2015 


\section{Oncogenesis}

B Lower Lifetime Risk of Cancer

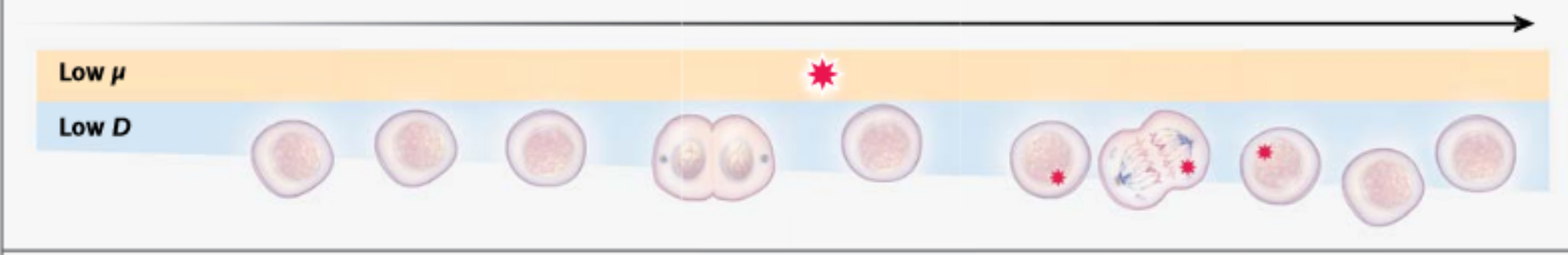

C Higher Lifetime Risk of Cancer

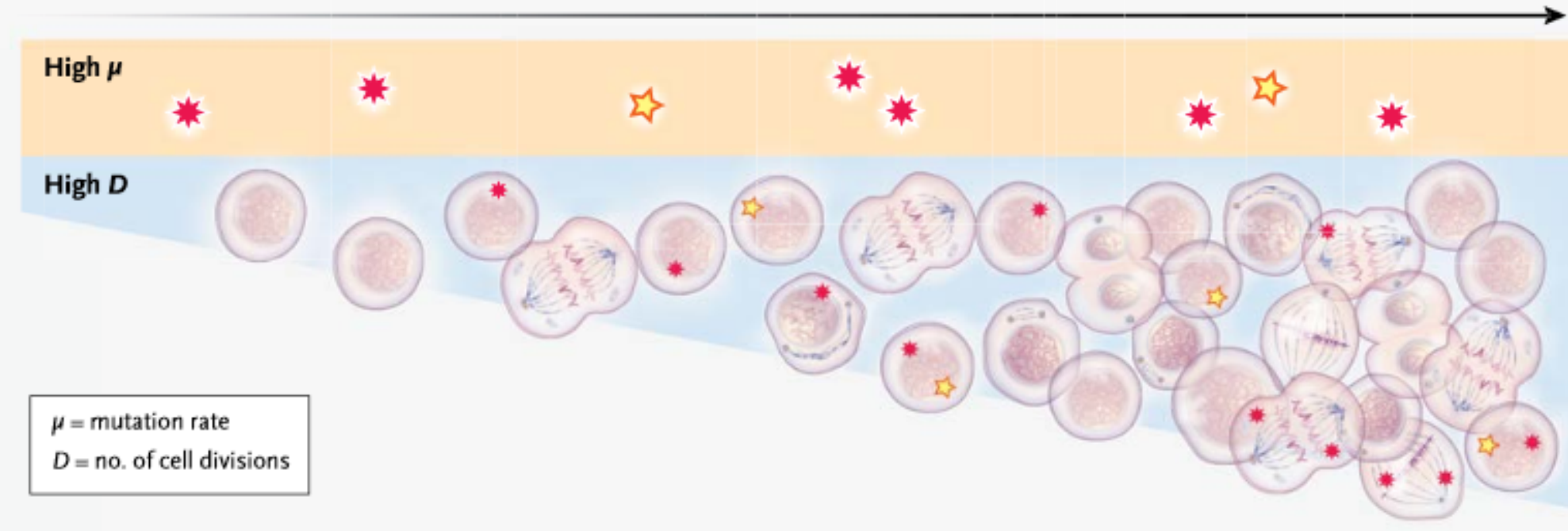

Figure 1. Discrete Stochastic Events in the Change from a Normal Cell to a Cancer Cell.

......Clonal Evolution

L. Luzzatto, P.P. Pandolfi, NEJM 373, 84, 2015 


\section{Evolution and Cancer}

\section{Priciples of Evolution}

1. Mutations by Chance, limited by possible options

2. Opportunity: Survival advantage under the given conditions

3. Selection of the fittest

Cancer Cells

- Acquire Immortality

- Increasing loss of controls driven by entropy 


\section{Oncogenesis: Conclusion}

- Cancer is an aquired genetic disease

- $\quad$ Cancer is the continued evolution of cells within an individuum

- Oncogenesis and the clinical disease follow the Darwinian principles of evolution

- Genetic and epigenetic factors contribute to carcinogenesis and evolution

- Mutated genes/proteins may serve as molecular targets

- for small molecules, antibodies, CART cells

- as (neo)antigens for immune system recognition/attack

Pathophysiological hallmarks identify potential therapeutic pathways 


\section{Targeted Therapies}

- $\quad$ Small (designer) molecules

- Some Leukemias can now be "cured"

- Good results also in some solid tumors

- Monoclonal Antibodies

- Lymphoma, Leukemia: significantly improved survival

- Lung cancer, colon cancer, others

- Transgenic T Cells (CART Cells)

- Highly active in leukemias

- In preclinical models also in solid tumors 


\section{Harnessing the Immune System}

1. non-specific defense mechanisms

2. Immunisation, Prophylactic - Therapeutic: e.g. HPV

3. Liberating endogenous immunity: Immune Checkpoint Inhibition 


\section{Clonal Evolution: The Hydra Challenge}

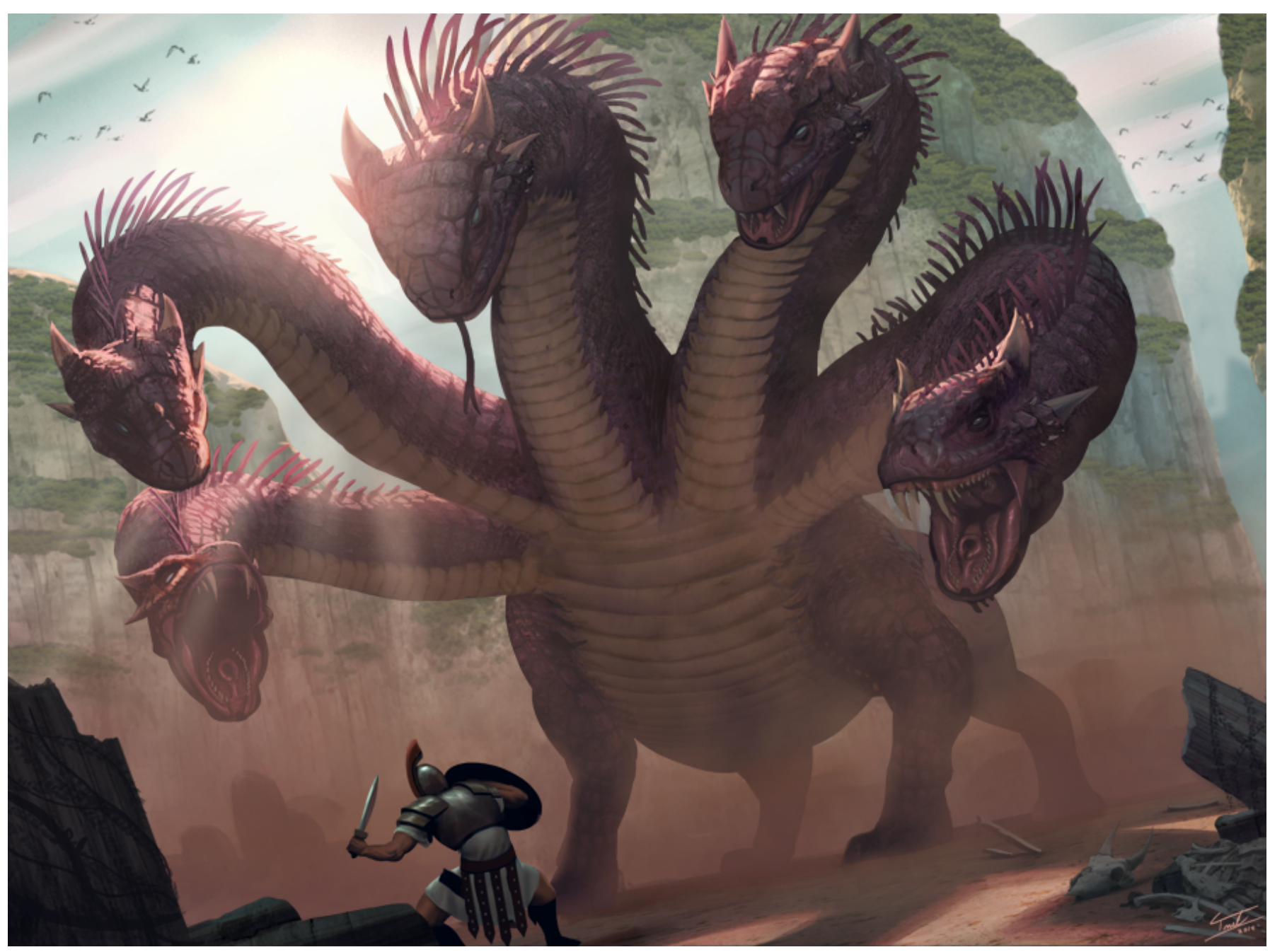




\section{Genetic Evolution - Clonal Evolution}

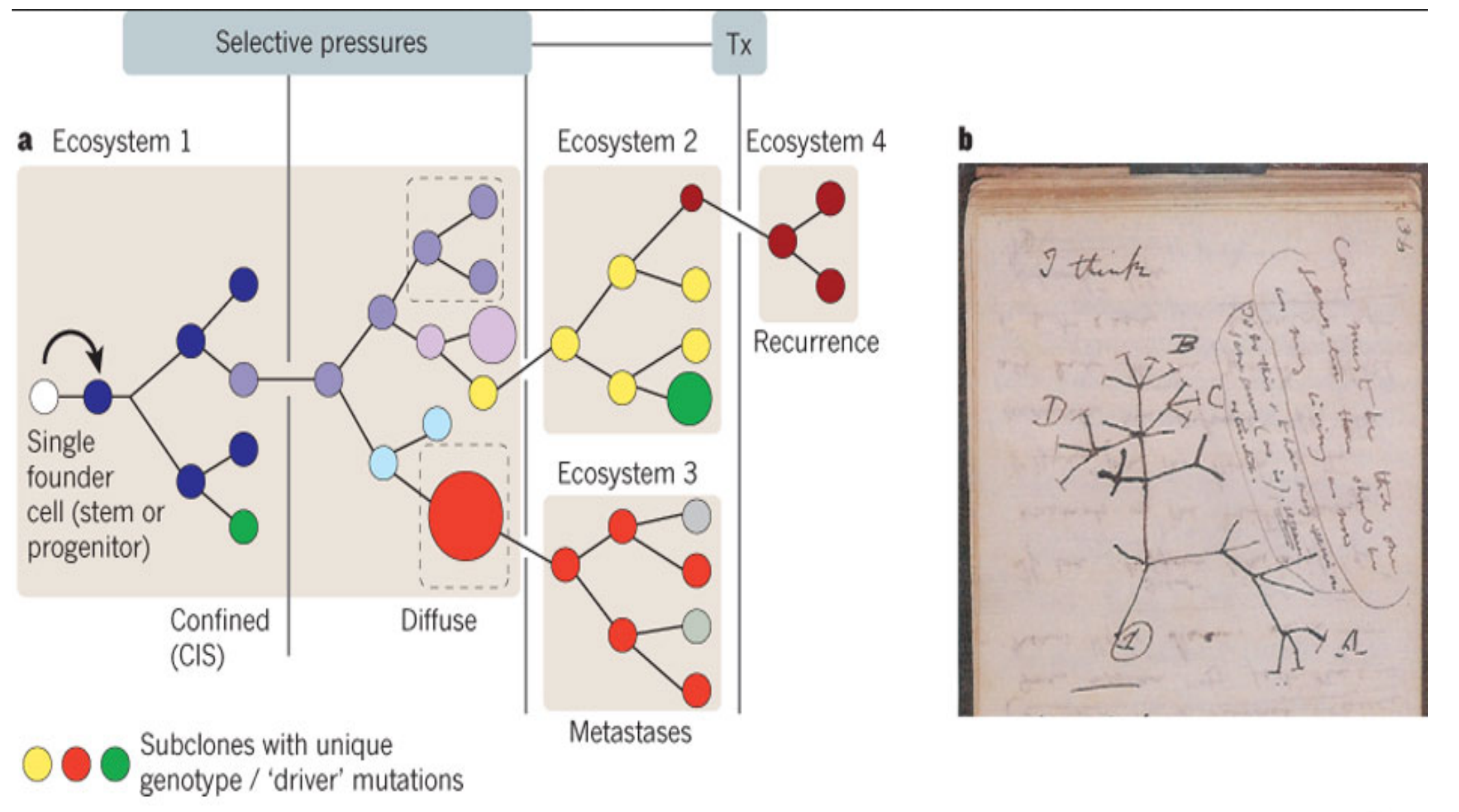

Clonal evolution in cancer, M. Greaves, C.C. Maley, Nature 481, 306-313, 2012 


\section{Clonal Evolution}

Figure 2

UNIVERSITÄTS

NNERE MEDIZIN I
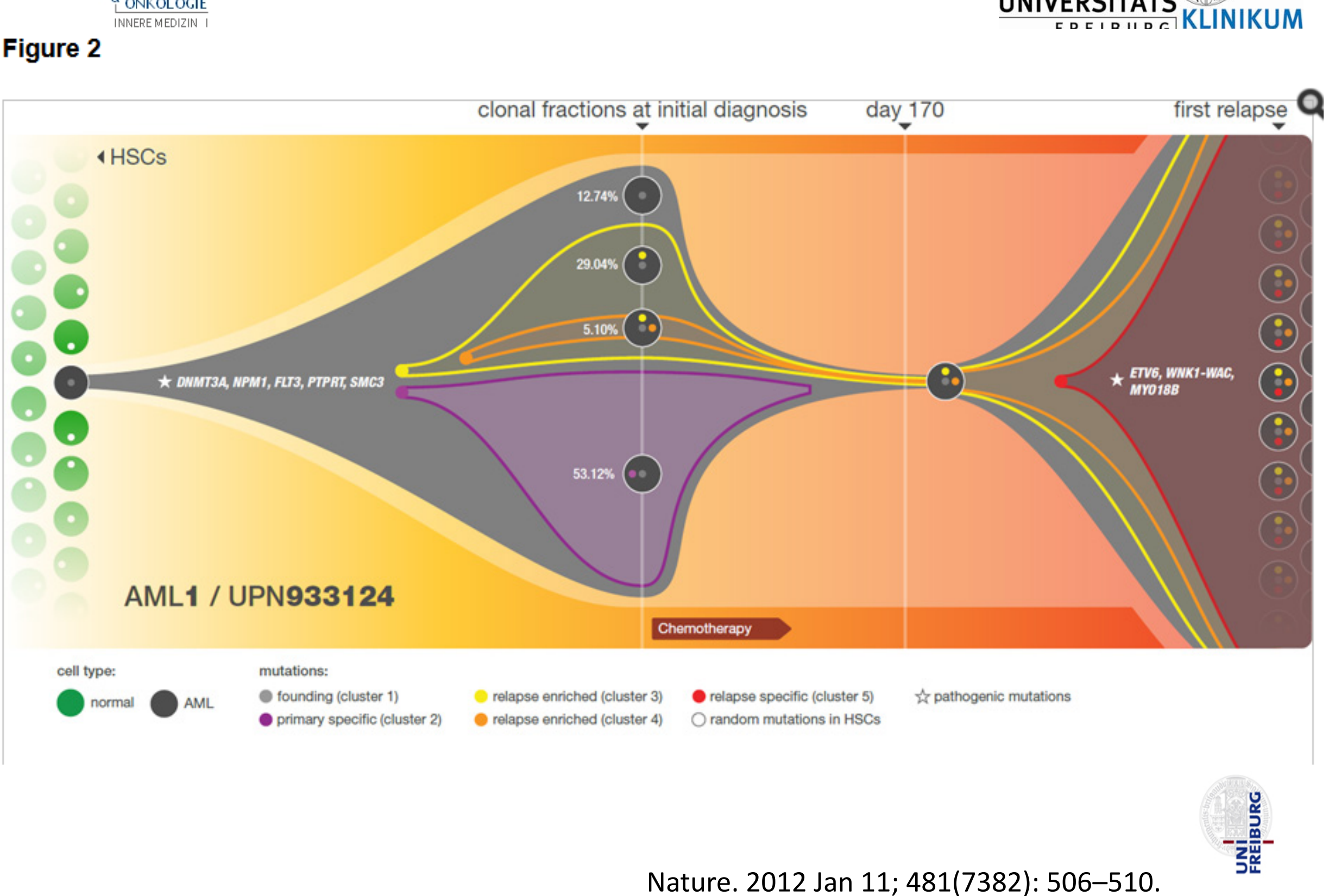


\section{Individualized/Personalized Evidence- Based Therapy}

Cancers are different

- from Patient to Patient

- within one Patient over Time

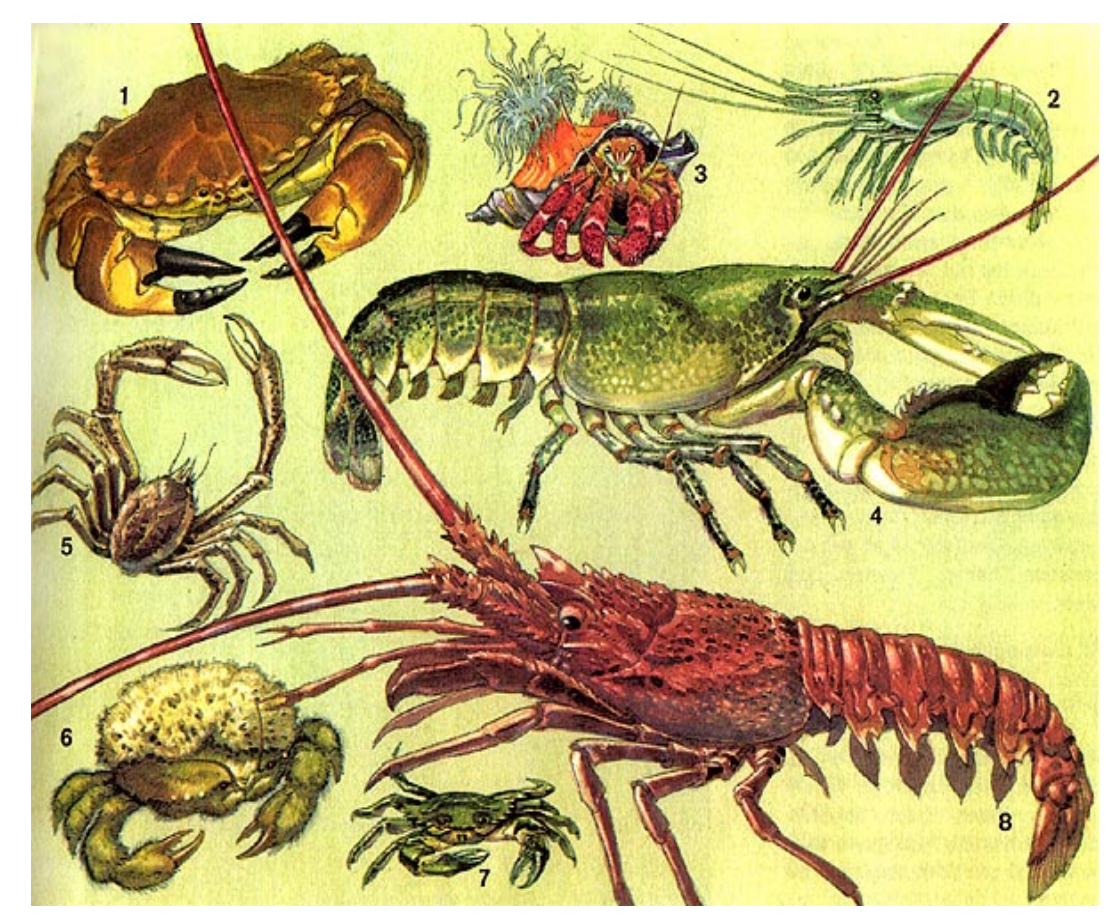

Humans differ

- in their genetic program

- in comorbidities

- in their values, dreams and priorities

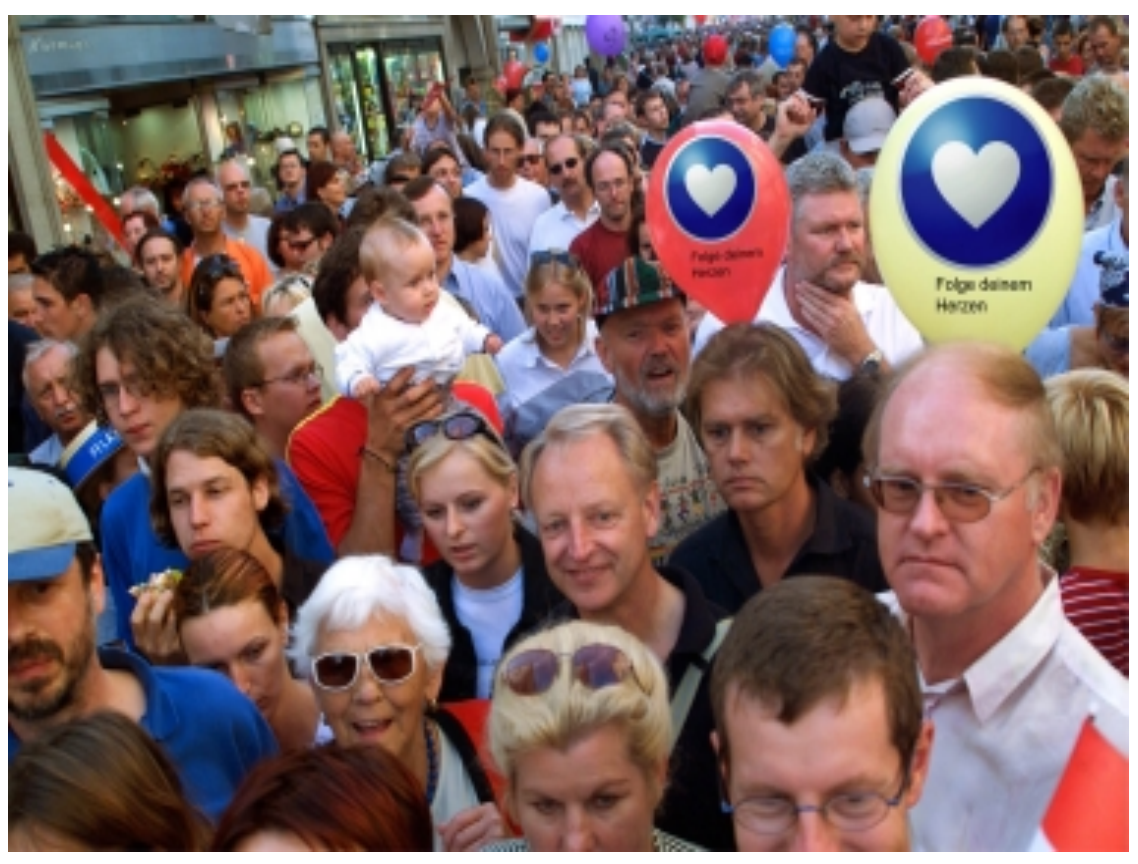

Variability Necessitates Individual Therapeutic Strategies 


\section{Precision Medicine - Bringing it to the Patient What is "precise" for the Individual?}

\section{The Old Model}

1. Phase I, II, III Studies in large, higly selected cohorts of patients aiming for improved response rates

2. Standard of Care in Guidelines for unselected patients focussed on clinical/pathological cancer type and stage

\section{The New Model}

Studies in small cohorts aiming for high response rates focussed on Molecular Signature of Cancer

\section{The Innovation Pathway}

Focussed on the optimal therapeutic strategy for the Individual Patient

Based on all available evidence And careful risk - benefit analysis 


\section{The 1971 War on Cancer Revisited 2016}

1. Reconnaisance

- Understanding cancer: Oncogenesis and Clonal Evolution

2. Identify Therapeutic Targets

- Cancer Pathways, molecular and metabolic

- Cancer Molecules

3. Strengthen the Defenses

- Activate the immune system

4. My Strategy for "Winning the War"

- Develop the innovation pathway - PEBM

- Identify novel therapeutic objectives; stable disease vs. Remission

- Evaluate guidelines and Tumor Boards as management standard

- In silico experiments, modeling, simulation: Artificial intelligence

- Search for missing „links“, Phenotype - genotype fallacy 


\section{Carcinogenesis: Simulations and Machine Learning}

The virtual experiment:
$>10$ variables
$>\quad$ With 5 concentrations
$>\quad$ At 10 timepoints
$>10 \mathrm{e} 50$ possibilities

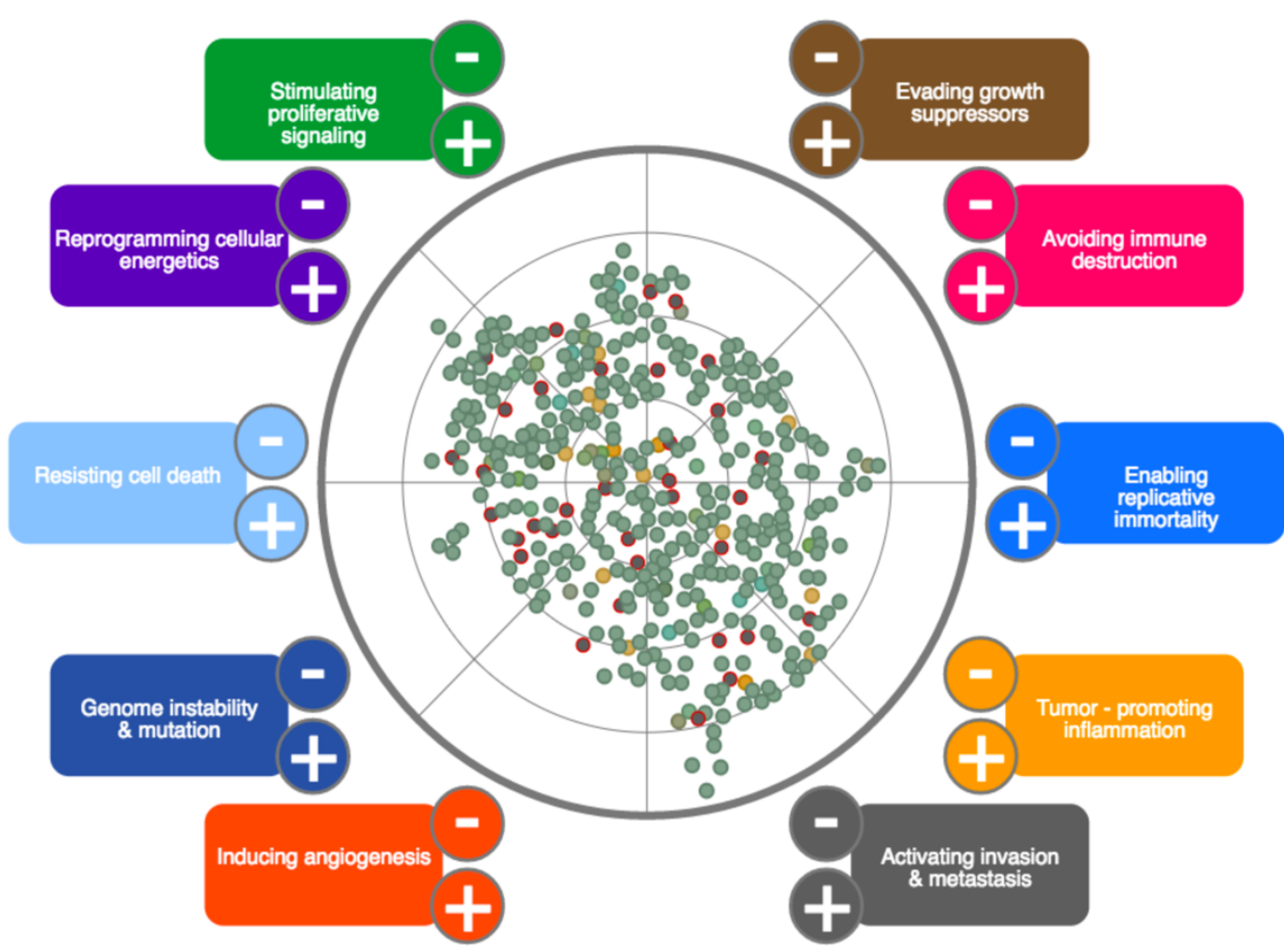

Total: 4417 Current: 390 Died: 4027 space-consuming: 3898 Growing: 0.101

Task: adjust input buttons to provide maximum number of cells 1. In virtual Petri dish 2. In output (Metastases) manual

Program

simulations

machinelearning 
"Mitosis" Computer Game 


\section{5: 10 Rules to Prevent Cancer}

1. Do not smoke.

2. Do not smoke.

3. Do not smoke.

4. Avoid carcinogens: Asbestos, UV-Light, Aflatoxine.

5. Diet: moderate in calories, salt, fat, little Alcohol. 6. 3x daily fresh fruit and vegetable.

7. Exercise and watch your weight.

8. Vaccination (Hepatitis B, HPV) and Treatment of chronic infections.

9. Good genes.

10. Good luck!! 


\section{Oncology - Still fighting Cancer}

\section{Thank you to the Speakers and Audience!}

My Mentors

My Colleagues

My Mentees and Alumni

Our Patients

The „Symposium“ Team

- Bärbel Schätzle

- Evgenia Alechine

- Stephan Seiler

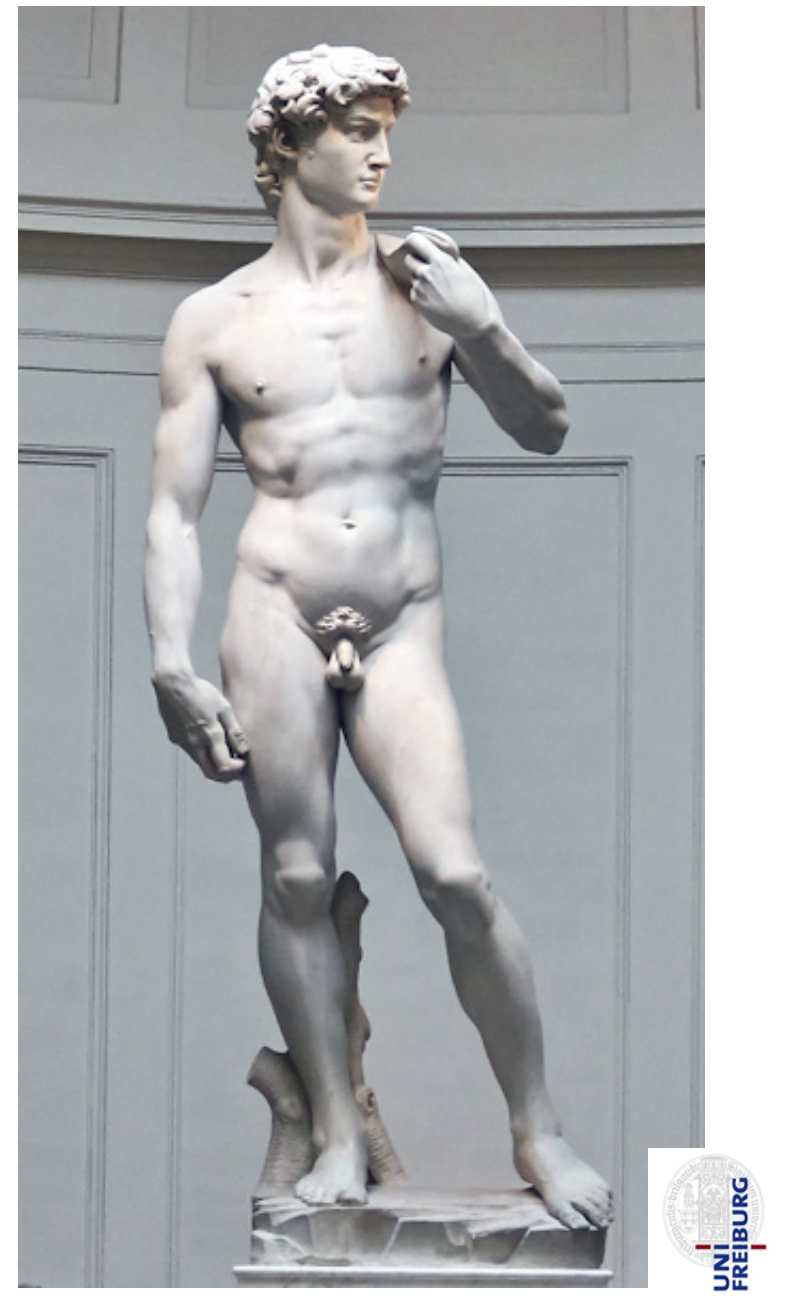




\section{Clonal Evolution: The Hydra Challenge}

\section{EVOLVING STRATEGIES}

Oncologists are adapting cancer-treatment strategies to

take into account how a tumour evolves.

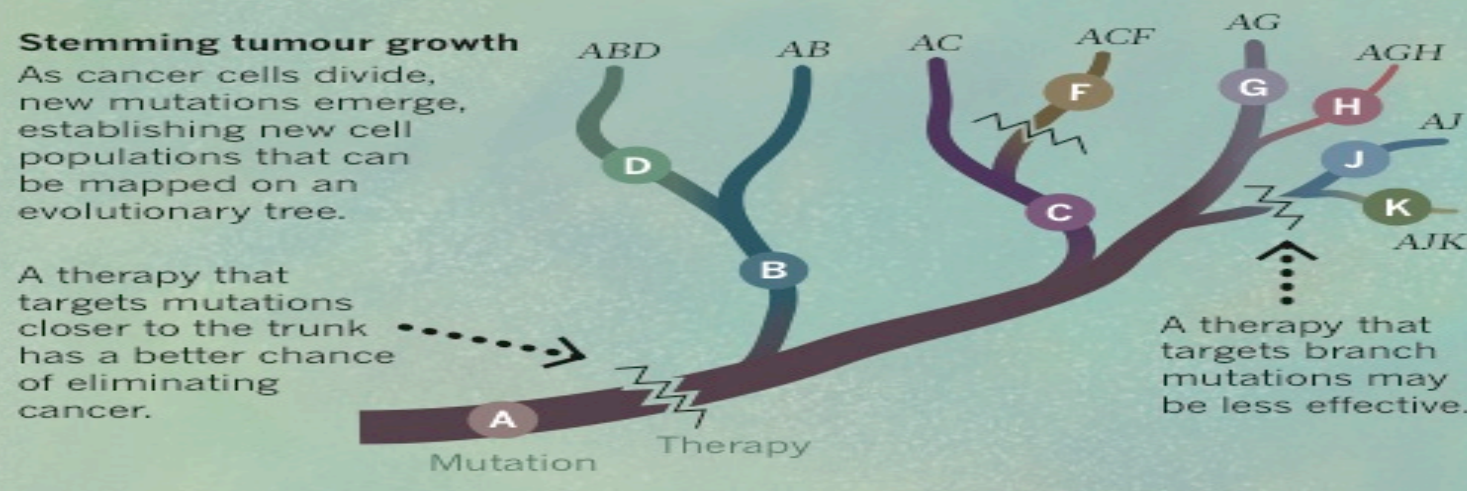

Adapting for balance

Cancer-cell populations compete, so completely killing cells that are sensitive

to a particular drug lets resistant cells grow unfettered. Adjusting dosage

according to tumour response could maintain balance in the populations.

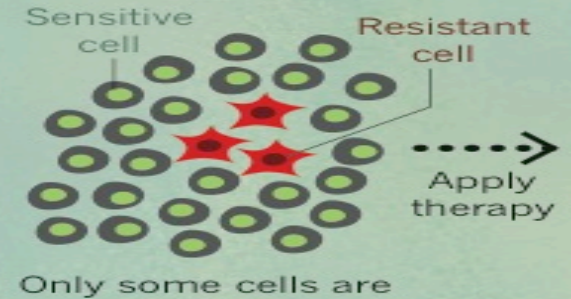

Only some cells are resistant.
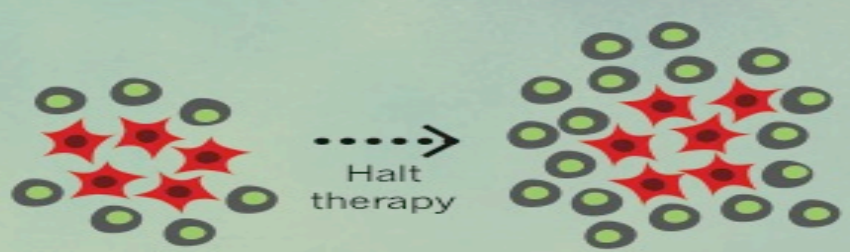

The tumour remains treatable.

\section{The double bind}

Developing resistance to one treatment can leave tumours vulnerable to others. Evolutionary modelling can suggest the best way to apply multiple therapies to almost eradicate resistant cells.

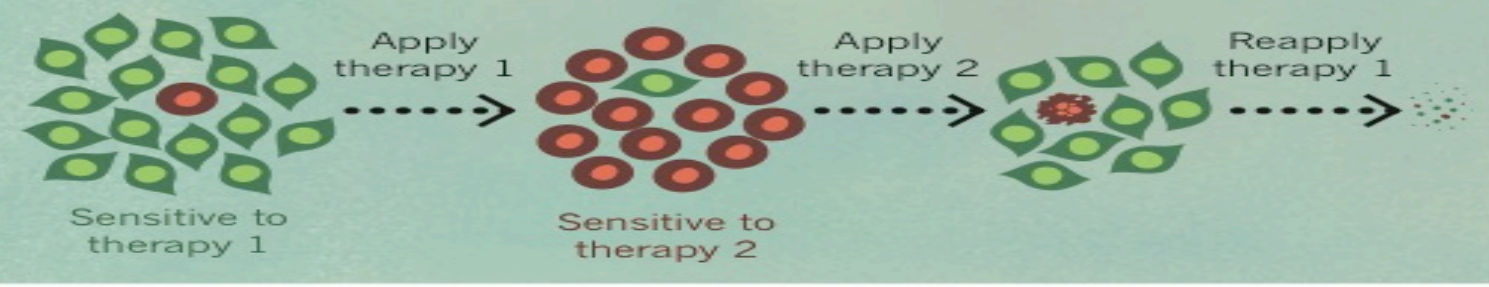

Cassandra Willyard

Cancer: An evolving threat

Nature 532, 166, 2016

„Tumours are subject to the same rules of natural selection as any other living thing."

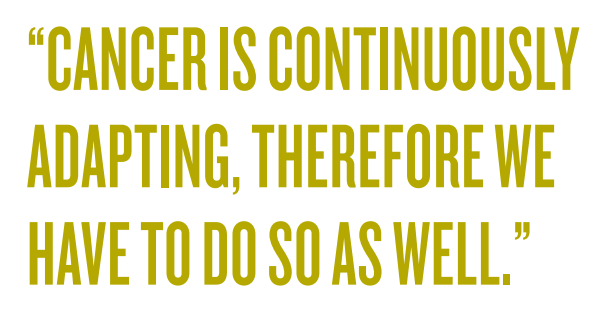
ADAPTING, THEREFORE WE HAVETODOSOASWELL." 
Cancer: Evolution und Adaptation

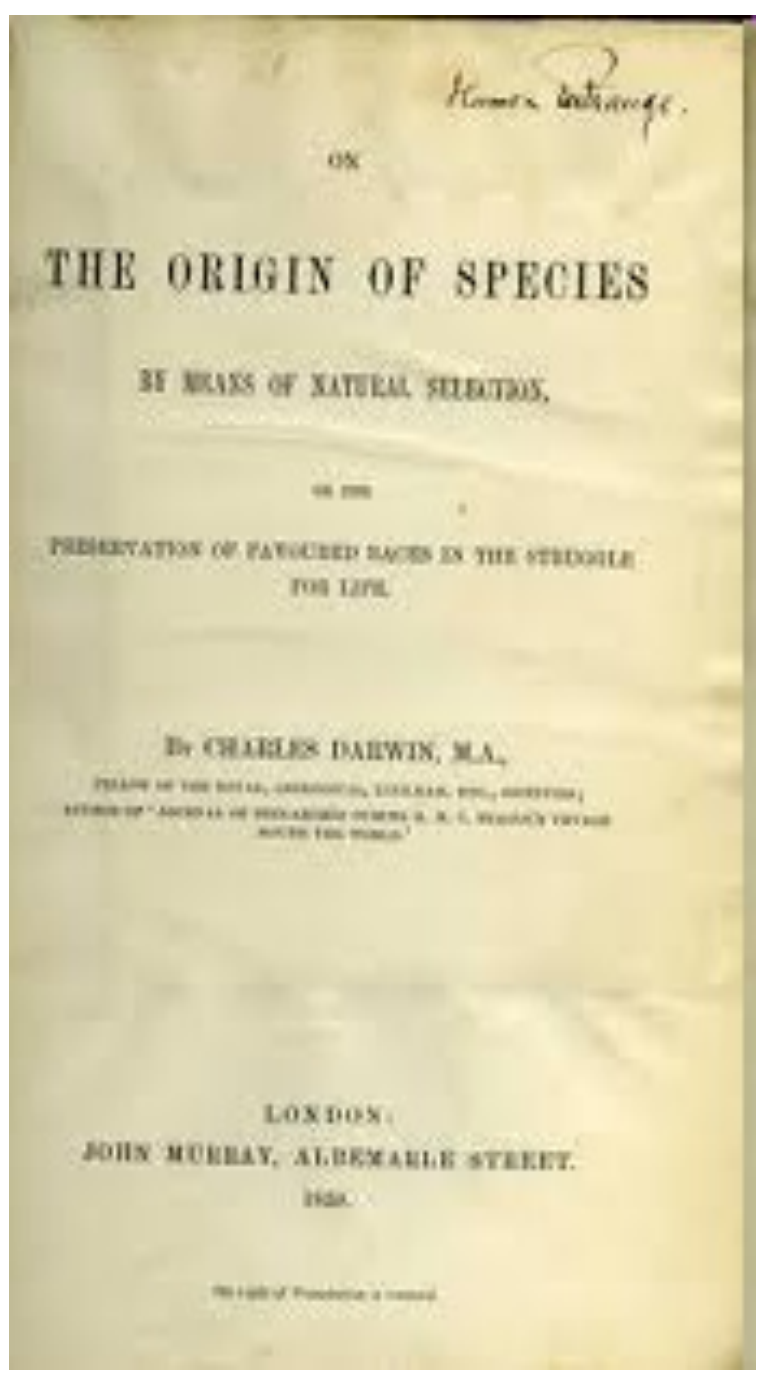

Genetic Evolution of DNA assures the longterm survival advantage of cancer cells

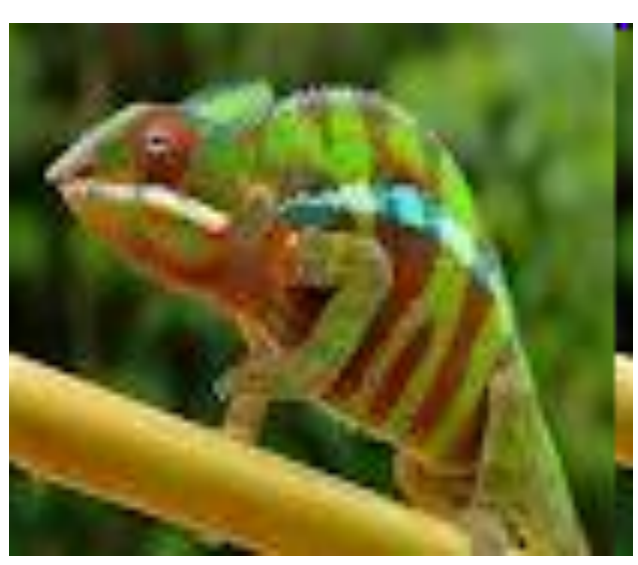

"Cancer is a moving target"
Epigenetic Adaptation assures the rapid adaptation to the environment

flexible Phenotype, e.g.

MET Transition

Cancer Stem Cell a "Mirage" 


\section{Oncogenesis}

\section{Factors in Oncogenesis}

\section{Chance $30 \%$ ? \\ 2. Other?}

Probability of Penetrance dependent on

1. Genetic Predisposition

2. Population Size

3. Proliferative Rate

4. Environmental Factors

5. 


\section{Harnessing the Immune System Immune Checkpoint Inhibition}

- numerous positive clinical trials demonstrating high efficacy and long-lastin remissions in Melanoma, various $\mathrm{ST}$, HD; others under investigation

- autoimmune side-effects 


\section{Oncology - The War on Cancer}

Albert Einstein

„Everything should be made as

simple as possible,

but not simpler." 